\title{
Extraction Method and Analysis of Cannabinoids in Cannabis Olive Oil Preparations
}

Antonella Casiraghi, Gabriella Roda, Eleonora Casagni, Cecilia Cristina, Umberto Maria Musazzi, Silvia Franzè, Paolo Rocco, Claudia Giuliani, Gelsomina Fico, Paola Minghetti, Veniero Gambaro

\author{
Authors

\section{Affiliation} \\ Dept. Scienze Farmaceutiche, Università degli Studi di Milano, \\ Milano, Italy \\ Key words \\ Cannabis sativa, Cannabaceae, olive oil preparation, \\ cannabinoids, extraction, GC/FID, GC/MS \\ received March 15, 2017 \\ revised October 31, 2017 \\ accepted November 3, 2017 \\ Bibliography \\ DOI https://doi.org/10.1055/s-0043-123074 \\ Published online | Planta Med (c) Georg Thieme Verlag KG \\ Stuttgart · New York | ISSN 0032-0943 \\ Correspondence \\ Gabriella Roda \\ Dept. Scienze Farmaceutiche, Università degli Studi di Milano \\ Via L. Mangiagalli 25, 20133 Milano, Italy \\ Phone: + 390250319328 , Fax: + 3902503219286 \\ gabriella.roda@unmi.it
}

Supporting information available online at

http://www.thieme-connect.de/products

\section{ABSTRACT}

Recently, an increasing number of pharmacists had to supply medicinal products based on Cannabis sativa L. (Cannabaceae), prescribed by physicians to individual patients. Cannabis olive oil preparation is the first choice as a concentrated extract of cannabinoids, even though standardized operative conditions for obtaining it are still not available. In this work, the impact of temperature and extraction time on the concentration of active principles was studied to harmonize the different compounding methods, optimize the extraction process, and reduce the variability among preparations. Moreover, starting from the cannabis inflorescence, the effect of temperature on tetrahydrocannabinolic acid decarboxylation was evaluated. For the analysis, a GC/MS method, as suggested by the Italian Ministry of Health, and a GC/flame ionization detection method were developed, validated, and compared.

\section{Introduction}

The medicinal use of Cannabis sativa L., (Cannabaceae), hereinafter cannabis, is being intensively investigated. The most common therapeutic indications [1] of C. sativa are undernutrition, chemotherapy-induced nausea and vomiting [2], neuropathic pain [3], spasticity and seizure in multiple sclerosis [4], glaucoma, and improving sleep [5]. Currently, only two cannabis-based medicinal products have obtained marketing authorization. They contain 1) the synthetic isomer of delta-9-tetrahydrocannabinol (THC) dronabinol (Marinol, AbbVie Inc.), used to manage loss of appetite associated with weight loss in acquired immune deficiency syndrome (AIDS) and nausea and vomiting associated with cancer chemotherapy in patients who have failed to respond adequately to conventional treatments or 2) the synthetic cannabinoid nabilone (Cesamet, Meda Pharmaceuticals Inc.). Another cannabis-based medicinal product is nabiximols (Sativex, GW Pharma Ltd.), a specific extract of $C$. sativa, used in multiple sclerosis to improve symptoms related to muscle stiffness, i.e., "spas- ticity". Seven other industrial pharmaceutical drugs based on cannabinoids are under development. Dried female flower tops of the cannabis plant are also available as standardized medicinal grade material. This possibility of treatment is a promising opportunity, as significant evidences show that plant-based medications are vastly superior to synthetic drugs because of a complex cannabinoid/terpene combination known as the "Entourage Effect" [1,6]. The use of the cannabis plant, vaporized or orally ingested, is admitted in several European countries. In the USA, it is not approved by Food and Drug Administration (FDA), even though it is legally allowed for certain medical conditions in several States [7].

C. sativa L. belongs to the family Cannabaceae, and is an annual dioecious plant with stems up to 2-5 m high, 3 to 9 palmatisect, alternate leaves with lanceolate, acute and serrate lobes, smooth nuts, and erect and glandular inflorescences: the male much branched, the female racemose [8].

THC, the main psychoactive constituent of $C$. sativa, and cannabidiol (CBD) are present in the plant as tetrahydrocannabinolic acid (THCA) and cannabidiolic acid (CBDA), respectively. The ac- 
idic forms, which are pharmacologically less active $[9,10]$, have to first be converted to the active neutral compounds. Decarboxylation is a temperature-dependent event and it can be reached by heating plant materials. At a few degrees over $100^{\circ} \mathrm{C}$, THCA decarboxylizes into THC [11]. At higher temperatures, between 180 and $200^{\circ} \mathrm{C}$, the vaporization of the cannabinoids that reside on the trichomes on the surface of flowers and leaves occurs, while at even higher temperatures $\left(230^{\circ} \mathrm{C}\right.$ and above) combustion takes place, producing smoke toxins. The outcome of the decarboxylation process is strongly influenced by operative conditions [12].

C. sativa for medical purposes is generally administered by two routes, either inhaled by means of a vaporizer or orally ingested. As vaporizers reach about $200{ }^{\circ} \mathrm{C}$, cannabinoids are available in the decarboxylated form. The oral formulations of cannabis may be in the form of a liquid extract, e.g., oil or tea, or capsules. After oral administration, the absorption of cannabinoids is slow and shows a limited oral pharmacokinetic. On the other hand, this route of administration is associated with a reduction of damage [13]. Liquid cannabis extracts may also be administered sublingually. Indeed, Sativex, a liquid extract containing THC and CBD in a $1: 1$ ratio, is available as an oromucosal spray [14].

Extraction in aqueous or organic solvents is a way to obtain a highly concentrated content of cannabinoids and other beneficial components. By using water, an herbal tea can be obtained, whose composition was investigated by Hazekamp et al. [15]. The results indicated that cannabis tea has only limited potency, as it is probably a saturated solution of THC. Ethanol extracts have also been evaluated, considering the higher solubility of the active principles in this solvent than in water [11]. The use of plant oil as an extraction solvent can be a safe alternative [16].

Recently, due to the approval by the Ministry of Health of a decree that regulates the cultivation, processing, and therapeutic uses of $C$. Sativa, there has been an increasing demand for the compounding of oily extracts obtained from the dried flowers. The need of a standardized protocol for oily preparations has grown accordingly, but until now, it has not been devised.

In this context, cannabis extraction was performed using olive oil and a standardized medicinal cannabis "flos" (according to pharmaceutical standards), purchased from a Dutch company and labelled as having a THC level standardized at 19-22\% and a CBD level below $1 \%$. Taking into account the above reported description of the cannabis fresh plant composition, it should be supposed that the flowering tops contain the acid forms of the two cannabinoids and, therefore, the value of $19-22 \%$ reported in the certificate of analysis should be the sum of the content of THC and THCA. Hazekamp [17] described this composition. Moreover, the chromatograms reported in the Analytical Monography Cannabis Flos [18] demonstrated that THCA is the major component among the active principles.

In this work, following a detailed morphological survey of plant material, the effect of extraction conditions on oily preparations and temperature on the cannabinoid decarboxylation in the cannabis inflorescence was evaluated. To harmonize extraction methods and temperatures, the Italian Society of Compounding Pharmacists (SIFAP) proposed to pharmacists six methods of preparation. The impact of temperature and extraction time on the con- centration of cannabinoids was studied to optimize the extraction and reduce the variability among preparations. Moreover, a GC/ MS method, as suggested by the Ministry of Health, and a GC/ FID (flame ionization detection) method were developed and validated, and the performances of the two different detectors were compared.

\section{Results and Discussion}

The morphological survey proved that the investigated plant material was comprised of female inflorescences. The pistillate flowers of $C$. sativa are indeed grouped into pairs in crowded, short pauciflore inflorescences at the axillae or terminals of branches. The flower consists of one unilocular ovary and of two elongated and hairy stigmas. A hood-shaped perianth surrounds the ovary, a typical characteristic of the family Cannabaceae ( $\vee$ Fig.1 A,B). The plant epidermis, especially at the perianth level, is densely covered by an indumentum composed of diverse kinds of trichomes ( $\triangleright$ Fig. 1 C). The investigated samples, even if dried, are quite well preserved, since trichome morphotypes are easily recognizable, although the epidermal surface appears deeply collapsed ( $\bullet$ Fig. 1 D).

Hooked hair-like lithocysts are invariably well preserved and are mostly visible on the leaf surfaces ( $\triangleright$ Fig. $1 \mathrm{D}, \mathbf{E}$ ). Their distribution patterning and the composition of the cystoliths have been used in the past in the forensic identification of marijuana [19].

Glandular hairs of various kinds have been described under different, debatable terms over time [20]. We chose, however, to use the existing terminology and, consistent with the criticism that emerged in the paper by [21], distinguished two main trichome groups. The first is-bulbous, with a uni- or bicellular head, a short, biseriate stalk and a 2-foot cell lying at the level with the epidermis [21]. We documented their distribution only for leaf laminas ( $\vee$ Fig. 1C). The second group is-capitate, with a head made up of 8-16 cells arranged in a single disc, surmounted by a wide subcuticular space, and a multiseriate stalk composed of 2-4 cell rows. The stalk is variable in length due the diverse elongation degree of the epidermal multiseriate foot (pseudo-stalks) supporting it. Thus, the so-called capitate-stalked glands and capitatesessile glands have been grouped together. They occurred on the inflorescence axis, on leaves and especially on pistillate bracts ( $\triangleright$ Fig. 1 E-G).

Due to the dense indumentum and to the overall small size of bulbous hairs, light microscope observations mostly involved capitate glands with long pseudo-stalks.

The localization of cannabinoid production in the head and stalk of capitate trichomes is largely confirmed by gas-liquid chromatographic evidences and by the identification of the candidate biosynthetic genes [22]. Copious secretory products fully covering the head and the stalk of capitates were observed ( $\bullet$ Fig. 1 G-J). These substances appear brown-colored and exhibited primary fluorescence under UV light ( $\bullet$ Fig. $\mathbf{1 ~ H - J )}$ ).

A redefinition of trichome nomenclature would be highly desirable. In this paper, however, we avoided recommending updated names to define the gland morphotypes, because an in-depth study of trichome ontogeny is essential in this regard. 

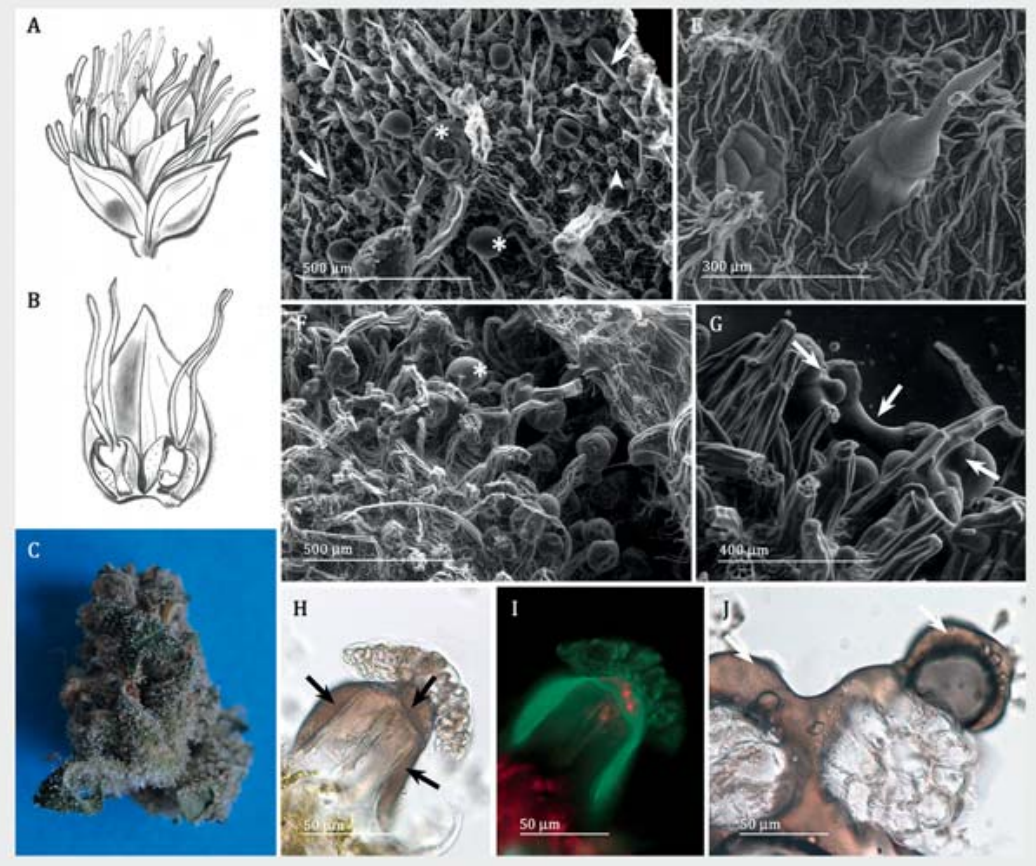

- Fig. 1 A, B Illustrations of the typical structure of a female inflorescence (A) and of a single female flower (B) in the family Cannabaceae (drawings by M. Bottoni.). C Macrograph showing one of the investigated samples of $C$. sativa. Note the crowded arrangement of the flowers in the female inflorescence and the dense pubescence over the plant epidermis. D-G ESEM micrographs. D Leaf adaxial surface showing hooked hair-like lithocysts (arrows), bulbous (arrow head), and capitate (asterisks) trichomes. E Particulars of the leaf adaxial surface with deeply collapsed epidermal cells and a well-preserved hooked hair-like lithocysts (on the right) and a capitate hair with a short pseudo-stalk (on the left). Note the breakage of the cuticular sheat and the head cells arranged in a single disc. F Abaxial surface of a pistillate bract showing abundant capitates with a long pseudo-stalk. Most of them appear headless, with collapsed pseudo-stalks, however, well-preserved glandular heads with intact cuticular sheats are observed (asterisks). G Particular of the abaxial surface of a pistillate bract. Note the copious secretory products (arrows) covering almost the whole capitate trichomes. H-J LM micrographs showing capitate trichomes with long pseudo-stalks. $\mathbf{H}$ Hair longitudinal view in bright field. The secretory products (arrows) flowing along the pseudo-stalk appear dark brownish. I Hair longitudinal view under UV light. The secretory products (arrows) exhibit primary fluorescence. J Hair crosswise view in bright field evidencing the head cell number and abundant brownish secretory material (arrows).

For the analysis of cannabinoids, a GC/MS and a GC/FID method were developed and validated. Both methods showed adequate specificity, linearity (Table 1S, Supporting Information), accuracy (Table 2S, Supporting Information), precision (Table 3S, Supporting Information), limit of detection (LOD), and limit of quantitation (LOQ) for the evaluation in oily extracts, demonstrating that besides the MS detector, the FID yielded satisfactory results.

Both GC methods were therefore used for the analysis of cannabinoids contained in several olive oil preparations compounded by Italian pharmacists according to the conditions reported in - Table 1. Preparation methods consisted of two steps: i. heating of the cannabis material to obtain cannabinoid decarboxylation, before the extraction of the active principles (series $M 1, M 2$, M3), and ii. maceration in olive oil (series A, B, C). The results obtained from the analysis of the olive oil preparations with the GC/ FID technique are shown in $>$ Table 2 . The results obtained with the GC/MS method showed concentrations of analytes in the range $\pm 0.05 \%$ of those obtained with the FID detector.

Pharmacists used all of the six different preparation methods proposed by SIFAP. Three different treatments of cannabis before
- Table 1 Experimental conditions related to the heating of cannabis flos (series M1, M2, M3) and the extraction in oil (series A, B, C), as proposed to pharmacists for the compounding of olive oil extracts.

\begin{tabular}{|c|c|c|c|}
\hline \multirow{3}{*}{ Extraction in oil } & \multicolumn{3}{|c|}{ Heating of cannabis flos } \\
\hline & M1 & M2 & M3 \\
\hline & $\begin{array}{l}115^{\circ} \mathrm{C} \text { for } \\
40 \mathrm{~min}\end{array}$ & $\begin{array}{l}145^{\circ} \mathrm{C} \text { for } \\
30 \mathrm{~min}\end{array}$ & $\begin{array}{l}\text { Room } \\
\text { temperature }\end{array}$ \\
\hline $\mathrm{A}-70^{\circ} \mathrm{C}$ for $40 \mathrm{~min}$ & M1A & $\mathrm{M} 2 \mathrm{~A}$ & II \\
\hline $\mathrm{B}-100^{\circ} \mathrm{C}$ for $120 \mathrm{~min}$ & M1B & $\mathrm{M} 2 \mathrm{~B}$ & M3B \\
\hline $\mathrm{C}-110^{\circ} \mathrm{C}$ for $120 \mathrm{~min}$ & II & II & M3C \\
\hline
\end{tabular}

maceration were applied. Heating at $115^{\circ} \mathrm{C}$ for $40 \mathrm{~min}$ (M1) or at $145^{\circ} \mathrm{C}$ for $30 \mathrm{~min}$ (M2) to obtain the conversion of THCA into THC. In the third method (M3), no heating was carried out and, as expected, in samples 16-18 ( $\triangleright$ Table 2 ), compounded under conditions M3B (maceration in olive oil at $100^{\circ} \mathrm{C}$ for $120 \mathrm{~min}$ ) and $\mathrm{M} 3 \mathrm{C}$ (maceration in olive oil at $110^{\circ} \mathrm{C}$ for $120 \mathrm{~min}$ ), a higher content of 
- Table 2 Cannabinoid content (\% w/w) in olive oil preparations obtained with standardized medicinal cannabis flos.

\begin{tabular}{|c|c|c|c|}
\hline $\begin{array}{l}\text { Olive oil } \\
\text { preparation }\end{array}$ & Method & \% THC & \% THCA \\
\hline $\mathbf{1}$ & M1A & 0.80 & 0.20 \\
\hline $\mathbf{2}$ & M1A & 1.36 & 0.10 \\
\hline $\mathbf{3}$ & M1B & 2.07 & $<0.10$ \\
\hline $\mathbf{4}$ & M1B & 1.27 & $<0.10$ \\
\hline $\mathbf{5}$ & M1B & 1.75 & $<0.10$ \\
\hline $\mathbf{6}$ & M1B & 1.52 & 0.26 \\
\hline $\mathbf{7}$ & M1B & 1.45 & $<0.10$ \\
\hline $\mathbf{8}$ & M1B & 1.88 & $<0.10$ \\
\hline $\mathbf{9}$ & M1B & 1.98 & $<0.10$ \\
\hline $\mathbf{1 0}$ & M1B & 1.91 & $<0.10$ \\
\hline $\mathbf{1 1}$ & M1B & 2.00 & $<0.10$ \\
\hline $\mathbf{1 2}$ & M2A & 1.50 & $<0.10$ \\
\hline $\mathbf{1 3}$ & M2A & 1.24 & $<0.10$ \\
\hline $\mathbf{1 4}$ & M2B & 1.57 & $<0.10$ \\
\hline $\mathbf{1 5}$ & M2B & 1.42 & 0.16 \\
\hline $\mathbf{1 6}$ & M3B & 0.30 & 1.50 \\
\hline $\mathbf{1 7}$ & M3B & 0.55 & 0.96 \\
\hline $\mathbf{1 8}$ & M3C & 0.83 & 0.69 \\
\hline axperimental conditions reported in & $\mathbf{2}$ Table 1. THC: delta-9-tetrahy- \\
\hline drocannabinol, THCA: tetrahydrocannabinolic acid & \\
\hline & & & \\
\hline
\end{tabular}

THCA than that obtained by using other conditions was observed. On the contrary, when the heating of the plant material was performed, the conversion of THCA into THC was almost complete. As far as the time and temperature of maceration of the plant material in olive oil is concerned, significant differences were detected in only a few cases. In particular, results obtained by using M1A (heating of the plant material at $115^{\circ} \mathrm{C}$ for 40 min and maceration in olive oil at $70^{\circ} \mathrm{C}$ for $40 \mathrm{~min}$ ) or M1B (heating of plant material at $115^{\circ} \mathrm{C}$ for $40 \mathrm{~min}$ and maceration in olive oil at $100^{\circ} \mathrm{C}$ for $120 \mathrm{~min})$ were statistically different $(p<0.05)$. Nevertheless, this difference was not revealed in samples obtained using method M2, maybe due to the very low number of samples prepared.

Taking these preliminary results into consideration, the effect of heating on the decarboxylation of THCA and the extraction conditions were further investigated using seized cannabis, obtained by the judicial authority, with the aim of developing a standardized protocol for this kind of preparation.

As previously discussed, the cannabinoids in flowering tops are mainly present in acidic form and they can be rapidly converted into their "neutral" pharmacologically active analogues under the influence of heat or extended storage. In the case of preparations intended for oral use, relatively low temperatures are usually involved. The effect of heating cannabis flowering tops from 85 to $145^{\circ} \mathrm{C}$ is shown in $\mathbf{F i g . 2}$. Heating was performed in a closed glass container to prevent terpene loss. For comparison, the content of untreated cannabis is also reported. In this case, a very mild heating $\left(35^{\circ} \mathrm{C}\right)$ was used to eliminate residual humidity. Up

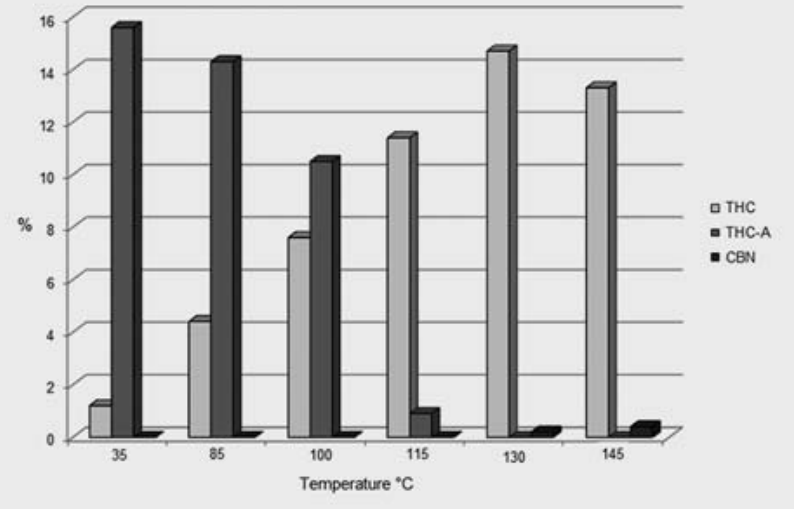

- Fig. 2 Cannabinoid content (\% w/w) in seized cannabis heated at different temperatures for $40 \mathrm{~min}$.

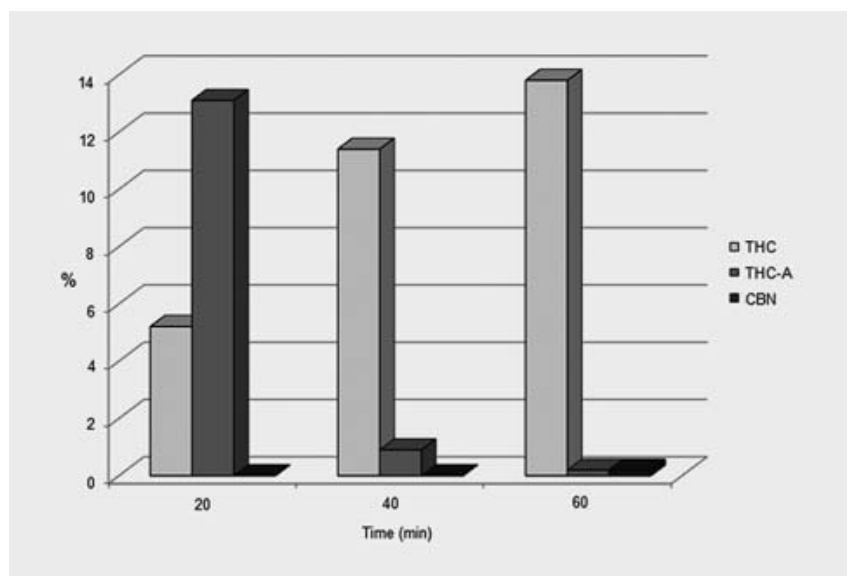

- Fig. 3 Cannabinoid content $(\% \mathrm{w} / \mathrm{w})$ in seized cannabis heated at $115^{\circ} \mathrm{C}$ for different times.

to $100^{\circ} \mathrm{C}$, the amount of $\mathrm{THC}$ is lower than that of the corresponding acidic cannabinoid. Below $115^{\circ} \mathrm{C}$, the levels of $\mathrm{CBN}$ were always below the LOQ, indicating a low decomposition rate of THC. The decarboxylation of THCA is complete over $130^{\circ} \mathrm{C}$. At this temperature, increasing amounts of $\mathrm{CBN}$ were measured. $\mathrm{CBN}$ is a product of THC oxidation, and it is a relatively minor constituent in fresh cannabis. At room temperature, its appearance is due to the long storage time [23].

The temperature of $115^{\circ} \mathrm{C}$ was therefore considered the most suitable to treat cannabis flowering tops before oil extraction. The effect of this temperature on THCA decarboxylation in the plant material kept in the oven for different periods of time was also investigated ( $\boldsymbol{F}$ Fig. $\mathbf{3}$ ). A prolonged heating time was equivalent to a higher temperature. The amount of THC improved, but the degradation product was also detected. If a high content of THC is required, without degradation effects, $115^{\circ} \mathrm{C}$ for $40 \mathrm{~min}$ is the best condition for the treatment of the flowering tops.

Then, time and temperature of extraction were studied. Results for the extracted amounts are reported in $>$ Table 3 . The 
lowest temperature seemed to be less efficient in the extraction, while at $100^{\circ} \mathrm{C}$, results obtained after 40 or 120 min were not significantly different. Therefore, a reduced extraction time was considered the best option. At this point, the repeatability of the extraction method was evaluated preparing six samples in the optimized conditions. The variability of the concentration of the active principles in these preparations was limited, as the mean content of THC, expressed as a percentage, was $1.47 \pm 0.14$, while THCA was present in only two samples in the amount of $0.2 \%$ w/w. CBN was never detected.

As repeatability was satisfactory, pharmacists were involved in the trial of a final standardized protocol: heating of cannabis plant material at $115^{\circ} \mathrm{C}$ for $40 \mathrm{~min}$ and extraction in oil at $100^{\circ} \mathrm{C}$ for 40 min. Operating with the optimized conditions, the THC content $(n=15$; mean $=1.55 \pm 0.18 \% \mathrm{w} / \mathrm{w})$ was not significantly different $(p=0.30)$ with respect to method M1B ( $\vee$ Table 1$)$, while the THCA content was reduced, being equal or below $0.1 \% \mathrm{w} / \mathrm{w}$. Samples of these preparations were kept in the refrigerator for 3 weeks and then analyzed again. The results obtained showed that the cannabis oils were stable and no variation in the THC content was observed.

In conclusion, this study highlighted that to obtain an olive oil preparation with a high content of THC, it is mandatory to decarboxylate the plant material before the maceration in olive oil. The analysis of the preparations obtained with the optimized method showed that it is possible to obtain olive oil extracts with a high content of THC and these preparations are homogeneous, even if prepared in different pharmacies. The GC/MS and GC/FID methods proposed showed features suitable to the analysis of cannabinoids contained in oily preparations, demonstrating that it is not strictly necessary to use an MS detector. In this frame, the development of an LC/UV method should be interesting.

This article does not contain any studies using human participants or animals. Informed consent was obtained from all individuals who participanted in this study.

\section{Materials and Methods}

\section{Plant material}

C. sativa, a variety containing THC $19-22 \%$ w/w (Bedrocan International), was used by the pharmacists. C. sativa was obtained from a judicial seizure, used as a reference standard with the permission of the judicial authority. Due to the restrictions established by the Italian Ministry of Health for universities to purchase medicinal C. sativa "flos", validation of the analytical methods and some experimental data were performed using cannabis seized on the illegal marked.

Botanical identification of all plant material was performed by Prof. Gelsomina Fico, botanist at the Department of Pharmaceutical Sciences of the University of Milan.

The voucher specimens consisted of dried female inflorescences. The voucher specimen for the marketed $C$. sativa was preserved and deposited at the Ghirardi Botanical Garden of the Department of Pharmaceutical Sciences of the University of Milan under the accession number 021/DISFARM. The voucher specimen for the seized $C$. sativa was preserved at the Laboratory of
- Table 3 Cannabinoid content (\% w/w) in olive oil obtained using heated seized cannabis at different conditions.

\begin{tabular}{|c|c|l|l|}
\hline Bath temperature $\left({ }^{\circ} \mathrm{C}\right)$ & Time $(\mathbf{m i n})$ & \% THC & \% THCA \\
\hline $\mathbf{7 0}$ & $\mathbf{4 0}$ & 1.21 & 0.00 \\
\hline $\mathbf{1 0 0}$ & $\mathbf{1 2 0}$ & 1.52 & 0.12 \\
\hline $\mathbf{1 0 0}$ & $\mathbf{4 0}$ & 1.55 & 0.11 \\
\hline
\end{tabular}

THC: delta-9-tetrahydrocannabinol, THCA: tetrahydrocannabinolic acid

Chemical and Toxicological Analysis of the Department of Pharmaceutical Sciences under the accession number 16/47.

\section{Morphological analysis}

A morphological investigation on the samples was performed combining a dual observation approach, macroscopic and microscopic. Firstly, macrographs of the whole intact samples were obtained with a Nikon D3300 digital camera mounted with a Sigma Lens 105 mm F2.8 EX DG Macro Nikon. Afterwards, a micromorphological survey on single leaves, pistillate bracts, and the inflorescence axis was carried out by means of light microscopy (LM) and environmental scanning electron microscopy (ESEM) in order to document the features of the glandular indumentum. A minimum of four replicates per each investigated plant part was used for the morphological analysis.

\section{Light microscopy}

Hand-made sections of each investigated plant part were observed under a Leitz DM-RB Fluo Optic microscope equipped with a digital camera (Nikon DS-L1). Observations were performed both in bright field and under UV light to evaluate the primary fluorescence of trichomes.

\section{Environmental scanning electron microscopy}

Small hand-prepared segments of each plant part were directly examined and photographed by means of a Philips XL30 ESEM, operating at $15 \mathrm{~kW}$.

\section{Chemicals and reagents}

Olive oil, Eur. Virgin, Ph. Eur. Olea europaea L.CAS Number 8001 25-0 (Farmalabor). Methanol (MeOH), toluene, O,N-bis(trimethylsilyl)trifluoroacetamide trimethylchlorosiloxane (BSTFA-1\% TMCS), methyl oleate ( $99 \%$ purity), THC $1 \mathrm{mg} / \mathrm{mL}$ in MeOH (purity $\geq 95.0 \%$ ), CBD $1 \mathrm{mg} / \mathrm{mL}$ in $\mathrm{MeOH}$ (purity $\geq 95.0 \%$ ), and CBN $1 \mathrm{mg} /$ $\mathrm{mL}$ in $\mathrm{MeOH}$ (purity $\geq 95.0 \%$ ) were purchased from Sigma-Aldrich. THCA $1 \mathrm{mg} / \mathrm{mL}$ in acetonitrile (purity $\geq 95.0 \%$ ) and CBDA $1 \mathrm{mg} /$ $\mathrm{mL}$ in acetonitrile (purity $\geq 95.0 \%$ ) were obtained from Cayman Chemical Company.

\section{Sample preparation of seized cannabis}

$50 \mathrm{mg}$ of seized cannabis were finely ground and added to $5 \mathrm{~mL}$ of methanol. The mixture was vortexed for $1 \mathrm{~min}$ and allowed to stand for $1 \mathrm{~min}$ three times. The mixture was centrifuged $(1789 \mathrm{~g}, 5 \mathrm{~min})$ and then $50 \mu \mathrm{L}$ ) of the supernatant were withdrawn and added with $50 \mu \mathrm{L}$ of the IS solution (methyl oleate, 

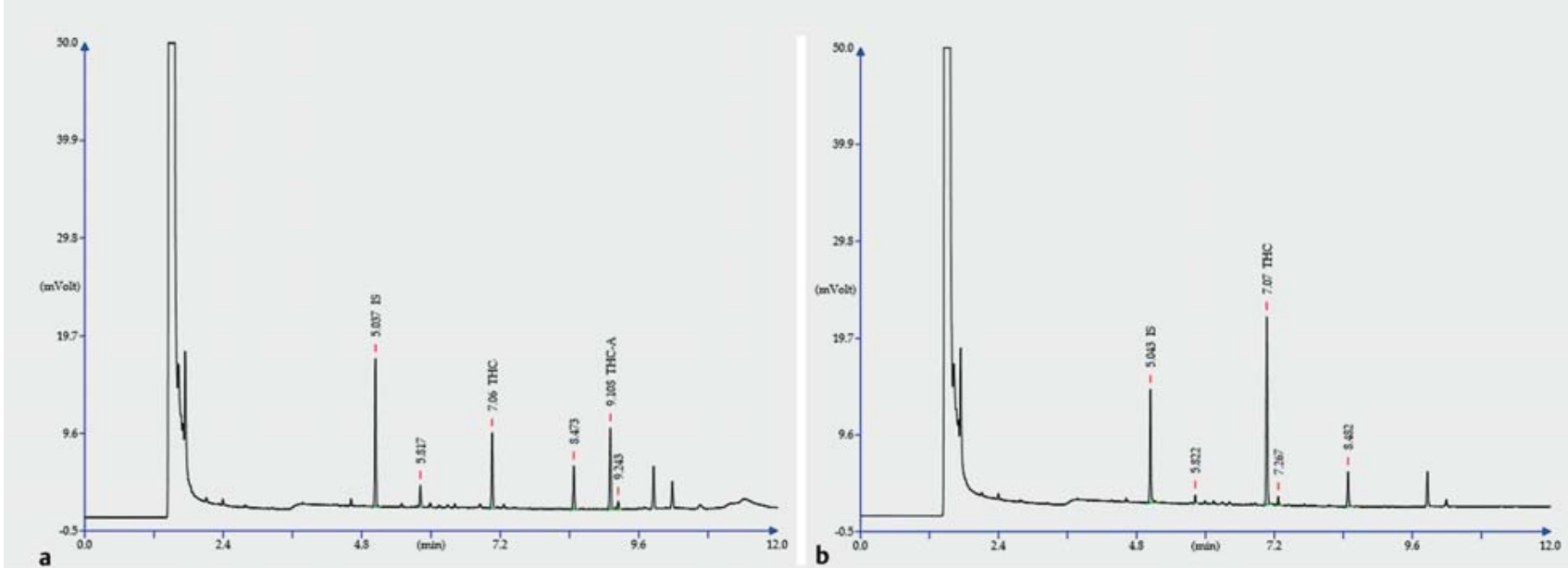

- Fig. 4 a GC/FID chromatogram of cannabis olive oil preparations obtained from non-heated material. b GC/FID chromatogram of cannabis olive oil preparations obtained from heated material.

$175 \mu \mathrm{g} / \mathrm{mL}$ in $\mathrm{MeOH})$. The solvent was evaporated and $50 \mu \mathrm{L}$ of BSTFA-1\% TMCS and $50 \mu \mathrm{L}$ of toluene were added. The mixture was vortexed and heated at $70^{\circ} \mathrm{C}$ for $30 \mathrm{~min}$.

\section{GC/FID}

GC/FID analyses were performed on a Trace 2000 Thermo Electron GC system (Thermo Fisher Scientific) with an FID detector. The GC was equipped with a DB-5MS UI 5\% diphenyl/95\% dimethylpolysiloxane $(30 \mathrm{~m} \times 0.25 \mathrm{~mm}$ i.d., film thickness $0.25 \mathrm{~mm}$ ) capillary column (Agilent Technologies).

The GC-FID system was operated under the following conditions: injector temperature $280^{\circ} \mathrm{C}$; split mode; split ratio: $30 / 1$; split flow: $39 \mathrm{~mL} / \mathrm{min}$. Helium was used as the carrier gas at a flow rate of $1.3 \mathrm{~mL} / \mathrm{min}$. The oven temperature program was as follows: $200-300^{\circ} \mathrm{C}, 10^{\circ} \mathrm{C} / \mathrm{min}$; final isotherm, 2 min; detector temperature: $300^{\circ} \mathrm{C}$. Hydrogen and air were used as the detector gases at a flow rate of $35 \mathrm{~mL} / \mathrm{min}$ and $350 \mathrm{~mL} / \mathrm{min}$, respectively. Nitrogen at a flow rate of $20 \mathrm{~mL} / \mathrm{min}$ was used as make-up gas. Time of analysis, $12 \mathrm{~min}$. Retention times of the analytes: CBD2TMS, $6.067 \mathrm{~min}$; THC-TMS, $7.068 \mathrm{~min}$; CBN-TMS, $7.718 \mathrm{~min}$; CBDA-3TMS, $7.918 \mathrm{~min}$; THCA-TMS, $9.115 \mathrm{~min}$; methyl oleate (IS), 5043 min (• Fig. 4).

\section{GC/MS}

The analyses were performed on a 5973 Hewlett Packard GC system, with a split-splitless injection system and an MS detector (Hewlett Packard) operated in the electron ionization (EI) mode (70 eV). The GC was equipped with a Rxi ${ }^{\circledR}-5$ ms (Crossbond ${ }^{\circledR}, 5 \%$ diphenyl $/ 95 \%$ dimethyl polysiloxane, $30 \mathrm{~m} \times 0.25 \mathrm{~mm}$ i.d., film thickness $0.25 \mathrm{~mm}$ ) capillary column (Restek). The GC/MS conditions were as follows: helium was used as the carrier gas at a flow rate of $1.2 \mathrm{~mL} / \mathrm{min}$, splitless mode ( $0.25 \mathrm{~min})$; injector temperature $280^{\circ} \mathrm{C}$; interface transfer line $300^{\circ} \mathrm{C}$; ion source $230^{\circ} \mathrm{C}$; oven temperature program, initial $70^{\circ} \mathrm{C}, 40^{\circ} \mathrm{C} / \mathrm{min}$ up to $180^{\circ} \mathrm{C}$, then $10^{\circ} \mathrm{C} / \mathrm{min}$ up to $300^{\circ} \mathrm{C}(6.25 \mathrm{~min})$.
The MS detector was operated in scan mode, acquiring ions from $\mathrm{m} / \mathrm{z} 50$ to 600 . The total analysis time was $21 \mathrm{~min}$. The retention times of the analytes were: IS (methyl oleate), 8.478 min (selected ions: 296, 264, 222 m/z); CBD - 2TMS, 9.709 min (selected ions: 390, 337, $301 \mathrm{~m} / \mathrm{z}$ ); THC - TMS, $10.748 \mathrm{~min}$ (selected ions: 386, 371, $315 \mathrm{~m} / \mathrm{z}$ ); CBN - TMS, 11.429 min (selected ions: 382, 368, $367 \mathrm{~m} / \mathrm{z}$ ); CBD - A - 3TMS, 11.704 min (selected ions 559, 491, $453 \mathrm{~m} / \mathrm{z}$ ); THC - A - 2TMS, $12.908 \mathrm{~min}$ (selected ions: 487, $502 \mathrm{~m} / \mathrm{z})(\triangleright$ Fig. 5).

\section{GC/flame ionization detection and GC/MS validation}

The specificity, accuracy, precision and linearity as well as the LOD and LOQ were evaluated on the olive oil preparations.

The specificity was assessed by analyzing blank olive oil. The lack of interfering peaks at the same analyte retention times conferred acceptable selectivity.

The linearity of the response was assessed for all the analytes using reference standards by plotting analyte/IS peak area ratios versus the percentage of the analyte in the standard solutions. Linearity was established on the olive oil preparations in the concentration range of $0.10-4.00 \%(w / w)$ for all analytes $(0.10 \%$, $0.25 \%, 0.50 \%, 1.00 \%, 1.50 \%, 2.00 \%, 4.00 \%$ ).

For the evaluation of linearity on the olive oil preparations, $50 \mu \mathrm{L}$ of each cannabinoid standard solution properly diluted and $50 \mu \mathrm{L}$ of olive oil were mixed, and $50 \mu \mathrm{L}$ of the IS solution (methyl oleate, $175 \mu \mathrm{g} / \mathrm{mL}$ in $\mathrm{MeOH}$ ) were then added. The solvent was evaporated and $50 \mu \mathrm{L}$ of BSTFA-1\% TMCS and $50 \mu \mathrm{L}$ of toluene were added. The mixture was vortexed and heated at $70^{\circ} \mathrm{C}$ for 30 min.

The intervals of linearity, the linearity equations, and correlation coefficients of the analytes obtained with the two methods are reported in Table 1S, Supporting Information, either in the case of the reference standards or olive oil preparations.

Accuracy was expressed as the percent recovery (\% REC) evaluated by analyzing, in triplicate, three solutions with a concentration of $0.50 \%$ and three solutions with a concentration of $1.50 \%$ of 

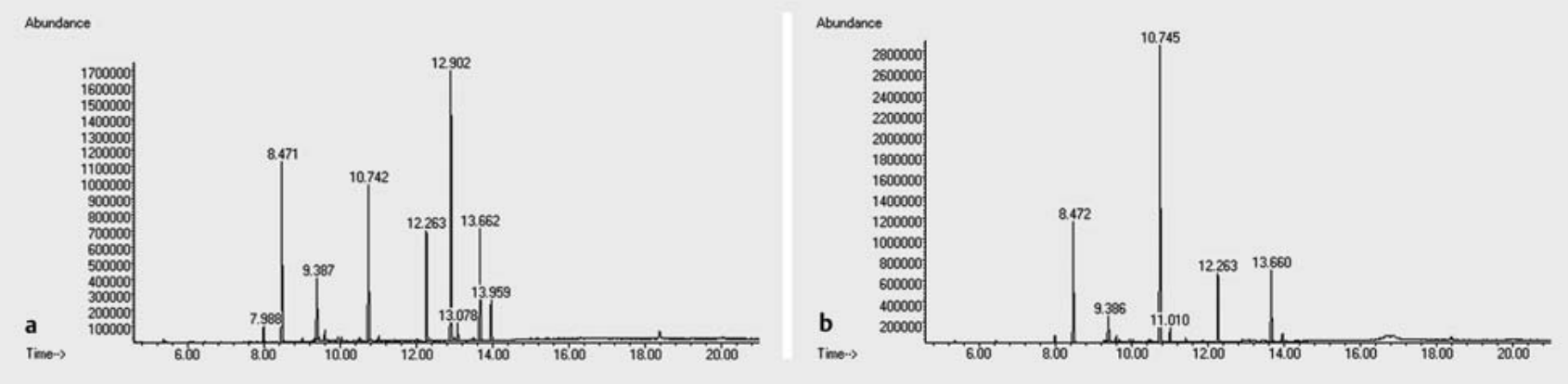

- Fig. 5 a GC/MS chromatogram of cannabis olive oil preparations obtained from non-heated material. b GC/MS chromatogram of cannabis olive oil preparations obtained from heated material.

all analytes. The averaged results were found to be satisfactory (Table 2S, Supporting Information).

Intraday precision was assessed by analyzing nine samples with a concentration of $0.50 \%$ and nine with a concentration of $1.50 \%$ of the analytes in the same day. The same samples were also analyzed on two other different days to evaluate inter-day precision. The results are reported in Table 35, Supporting Information.

The LOQ and LOD were also evaluated and were found to be, respectively, $0.10 \%$ and $0.03 \%$ for all analytes evaluated as the concentration of the analyte that gives a signal-to-noise ratio of at least 10 and 3, respectively.

\section{Effects of preheating}

To decarboxylate the acidic cannabinoids naturally present in plant material, seized cannabis was put in a closed glass vial and heated in an oven (T $5050 \mathrm{E}$, Heraeus) at 85, 100, 115, 130, $145^{\circ} \mathrm{C}$ for $40 \mathrm{~min}$. Unheated samples were used as a control for these experiments.

\section{Olive oil extract preparation}

Standardized medicinal cannabis flos: $5 \mathrm{~g}$ of cannabis were finely ground and added to $50 \mathrm{~mL}$ of olive oil. A mixer was used to further crumble the plant material. Then, the open beaker was put in a silicone oil bath preheated at fixed temperatures (70, $100,110^{\circ} \mathrm{C}$ ). The mixture was stirred for $40 \mathrm{~min}$ or $120 \mathrm{~min}$ and then immediately filtered to obtain the final oil according to methods reported in > Table $\mathbf{1}$.

Seized cannabis: a hashish sample seized by the judicial authority was used for the study of the extraction conditions. The composition, reported as $\% \mathrm{w} / \mathrm{w}$, was $\mathrm{CBD}=1.45 \%$, $\mathrm{THC}=14.49 \%$, $\mathrm{CBN}=0.66 \%, \mathrm{CBDA}=2.01 \%$, and $\mathrm{THCA}=4.11 \% .5 \mathrm{~g}$ of cannabis were finely ground and added to $50 \mathrm{~mL}$ of olive oil. A mixer was used to further crumble the plant material. Then, the open beaker was put in a silicone oil bath preheated at fixed temperatures ( 70 , $100^{\circ} \mathrm{C}$ ). The mixture was stirred for $40 \mathrm{~min}$ or $120 \mathrm{~min}$ and then immediately filtered by using three layers of a commercial gauze (Stericompress, sterile gauze bandages, $100 \%$ cotton, PIC solution) to obtain the final oil.

\section{Supporting information}

Range of linearity, linearity equations, and correlation coefficients (Table 1S), accuracy (Table 2S), and precision (Table 3S) for the two analytical methods are available as Supporting Information

\section{Acknowledgements}

We would like to thank the pharmacy members of SIFAP involved in this experimental work. Moreover, we wish to thank Dr. M. Bottoni for the realization of the botanical drawings and Dr. G. Porro for providing C. sativa for morphological analysis.

\section{Conflict of Interest}

There are no financial or other relations that could lead to a conflict of interest.

\section{References}

[1] Russo E, Guy GW. A tale of two cannabinoids: the therapeutic rationale for combining tetrahydrocannabinol and cannabidiol. Med Hypoth 2006; 66: 234-246

[2] Navari RM. Management of chemotherapy-induced nausea and vomiting: focus on newer agents and new uses for older agents. Drugs 2013; 73: 249-262

[3] Finnerup NB, Attal N, Haroutounian S, Mcnicol E, Baron R, Dworkin RH, Gilron I, Haanpää M, Hansson P, Jensen TS, Kamerman PR, Lund K, Moore A, Raja SN, Rice AS, Rowbotham M, Sena E, Siddall P, Smith BH, Wallace M. Pharmacotherapy for neuropathic pain in adults: a systematic review and meta-analysis. Lancet Neurol 2015; 14: 162-173

[4] Leussink VI, Husseini L, Warnke C, Broussalis E, Hartung HP, Kieseier BC. Symptomatic therapy in multiple sclerosis: the role of cannabinoids in treating spasticity. Ther Adv Neurol Disord 2012; 5: 255-266

[5] Haney M, Gunderson EW, Rabkin J, Hart CL, Vosburg SK, Comer SD, Foltin RW. Dronabinol and marijuana in HIV-positive marijuana smokers. Caloric intake, mood, and sleep. J Acquir Immune Defic Syndr 2007; 5: 545-554

[6] Adams M. FDA approves liquid marijuana for AIDS and cancer patients. Available at http://hightimes.com/news/fda-approves-liquid-marijuanafor-aids-and-cancer-patients/. Accessed July 28, 2016

[7] Jayesh P. Medical marijuana patient counseling points for health care professionals based on trends in the medical uses, efficacy, and adverse 
effects of cannabis-based pharmaceutical drugs. Res Soc Admin Pharm 2016; 12: 638-654

[8] Akeroyd JR. Cannabis L. In: Tutin TG, Burges NA, Chater AO, Edmondson JR, Heywood VH, Moore DM, Valentine DH, Walters SM, Webb DA, eds. Flora Europaea, vol. 1, 2. ed. Cambridge: Cambridge University Press; 1992: 78

[9] Lercker G, Bocci F, Frega N, Bortolomeazzi R. Cannabinoid acids analysis. Farmaco 1992; 47: 367-378

[10] Perrotin-Brunel H, Buijs W, van Spronsen J, van Roosmalenb MJE, Petersa C], Verpoorted R, Witkampa G]. Decarboxylation of $\Delta 9$-tetrahydrocannabinol: Kinetics and molecular modelling. J Mol Struct 2011; 987: 67-73

[11] Politi M, Peschel W, Wilson N, Zloh M, Prieto JM, Heinrich M. Direct NMR analysis of cannabis water extracts and tinctures and semi-quantitative data on $\triangle 9$-THC and $\triangle 9$-THC-acid. Phytochemistry 2008; 69: 562-570

[12] Veress T, Szanto JI, Leisztner L. Determination of cannabinoid acids by high-performance liquid chromatography of their neutral derivatives formed by thermal decarboxylation: I. Study of the decarboxylation process in open reactors. J Chromatogr A 1990; 520: 339-347

[13] Grotenhermen F. Harm reduction associated with inhalation and oral administration of cannabis and THC. J Cann Ther 2001; 1: 133-152

[14] GW Pharma Company. GW pharmaceuticals, summary of product characteristics, 2011. Available at https://www.gwpharm.com/productspipeline/sativex/patient-information/summary-product-characteristics. Accessed April 21, 2016
[15] Hazekamp A, Bastola K, Rashidi H, Bender J, Verpoorte R. Cannabis tea revisited: a systematic evaluation of the cannabinoid composition of cannabis tea. J Ethnopharmacol 2007; 113: 85-90

[16] Romano LL, Hazekamp A. Cannabis oil: chemical evaluation of an upcoming cannabis-based medicine. Cannabinoids 2013; 1: 1-11

[17] Hazekamp A. An evaluation of the quality of medicinal grade cannabis in the Netherlands. Cannabinoids 2006; 1: 1-9

[18] Analytical Monograph Cannabis Flos (flowers/granulated) OMC/Farmalyse BV, Version 7.1/November 28, 2014. Available at https://www. cannabisbureau.nl/Media/Default/PDF/Monograph Cannabis Flos Version 7.1 (November 28, 2014).pdf. Accessed November 28, 2014

[19] Evert RF. Esau's Plant Anatomy: Meristems, Cells, and Tissues of the Plant Body: Their Structure, Function, and Development, 3rd ed. Hoboken, New Jersey: John Wiley \& Sons; 2006

[20] Mahlberg PG, Kim ES. Accumulation of cannabinoids in glandular trichomes of Cannabis (Cannabaceae). J Ind Hemp 2004; 9: 15-36

[21] Dayanandan P, Kaufman PB. Trichomes of Cannabis sativa L. (Cannabaceae). Am J Bot 1976; 63: 578-591

[22] Happyana N, Agnolet S, Muntendam R, Van Dam A, Schneider B, Kayser O. Analysis of cannabinoids in laser-microdissected trichomes of medicinal Cannabis sativa using LCMS and cryogenic NMR. Phytochemistry 2013; 87: 51-59

[23] Izzo AA, Borrelli F, Capasso R, Di Marzo V, Mechoulam R. Non-psychotropic plant cannabinoids: new therapeutic opportunities from an ancient herb. Trends Pharmacol Sci 2009; 30: 515-527 